\title{
Scintigraphic distribution of lymphatic flow in the mediastinum after oral administration of radiolabeled lipid and its influx into blood circulation
}

\author{
Tetsu Sado, MD, Masami Sato, MD, Motoyasu Sagawa, MD, Kazuyoshi Shimada, MD, Yoshinori Okada, MD,
} Yuji Matsumura, MD, Tatsuo Tanita, MD, and Takashi Kondo, MD, Sendai, Japan

$\mathrm{D}$ uring thoracic operations, it is sometimes difficult to determine the route of collateral circulation of the thoracic duct, the site of chyle leakage, or both. In addition, the dynamics of lymph flow in the thoracic duct in diseased patients are impossible to understand with routine radiologic examinations, such as plain film, magnetic resonance imaging, and chest computed tomography (CT). Several diseases involve the thoracic duct, such as chylothorax, ${ }^{1,2}$ lymphangiomyomatosis, and lymphangiectasia. ${ }^{3}$ We herein report the case of a patient with a disorder of the thoracic duct in whom we successfully detected multiple flow routes of chyle, its abnormal accumulation in the mediastinum, and its influx into the blood circulation after the oral administration of iodine 123-labeled ( $\left.{ }^{123} \mathrm{I}\right) 15$-(piodophenyl)-3-R, S-methyl pentadecanoic acid (BMIPP). ${ }^{4}$

The patient was a 50-year-old woman who had an abnormal shadow in the medial side of the right lower lung field. Chest CT revealed a tumor-like soft tissue mass $3 \times 3 \mathrm{~cm}$ in size with fat density in the right lower anterior mediastinum and right thoracic effusion, suggesting diaphragmatic hernia (Figure 1, A). She was transferred to our hospital because of a slight increase of tumor size and dyspnea, and thoracotomy was carried out in June 1999. Operative findings showed a yellow, solid mass with pleural effusion identified as chyle. Macroscopically, we diagnosed her condition as liposarcoma with invasion to the thoracic duct. We removed the tumor and ligated the thoracic duct just above the diaphragm. Her condition was excellent after the operation. However, on postoperative day 13, a chest radiograph and a CT

From the Department of Thoracic Surgery, Institute of Development, Aging and Cancer, Tohoku University, Sendai, Japan.

This study was partly supported by grants-in-aid from the Ministry of Education, Science, Sports and Culture of the Japanese Government.

Received for publication Feb 2, 2001; accepted for publication Feb 28, 2001.

Address for reprints: Masami Sato, MD, the Department of Thoracic Surgery, Institute of Development, Aging and Cancer, Tohoku University, 4-1 Seiryo-machi, Aoba-ku, Sendai 980-8575, Japan (E-mail: m-sato@idac. tohoku.ac.jp).

J Thorac Cardiovasc Surg 2001;122:838-40

Copyright $\odot 2001$ by The American Association for Thoracic Surgery

$0022-5223 / 2001 \$ 35.00+0 \quad \mathbf{1 2 / 5 4 / 1 1 5 4 1 2}$

doi:10.1067/mtc.2001.115412 scan (Figure 1, $B$ ) showed dilatation of the mediastinum and right pleural effusion, and thus tube drainage was undertaken. Histologic examination revealed a granulomatous lesion with marked dilatation of the lymphatic vessels, suggesting occlusion or marked stenosis of the thoracic duct.

We performed contrast lymphangiography after cannulation of an afferent lymph vessel on the dorsum of the left foot but failed to detect the lymphatic flow in the mediastinum. Then ${ }^{123}$ I-BMIPP, a radiolabeled long-chain fatty acid that is usually used for cardiomyoscintigraphy, was administered orally and was subsequently imaged by means of radioisotope scintigraphy. Plasma activities of ${ }^{123}$ I-BMIPP were also monitored. Figure $1, D$, shows a scintiscan of this patient 300 minutes after administration of ${ }^{123}$ I-BMIPP. There were 3 routes of upward flow from the diaphragm and 3 transverse communications between them. At the left side of the aortic arch, marked accumulation of the isotope was also present. These scintiscans in the upper mediastinum of the patient were visualized 200 minutes after oral administration, whereas those of normal volunteers were visualized about 100 minutes after administration (Figure 1,C). Abnormal accumulation of the isotope was also observed the day after the examination. On the basis of these findings, we speculate that the influx of chyle into the blood circulation from the thoracic duct was severely impaired. However, the plasma activities of ${ }^{123}$ I-BMIPP after its oral administration gradually increased (Figure 2). This means that the thoracic duct was not obstructed completely. Low-fat diet therapy was carried out for about a month, and the drainage tube was then removed. The patient was discharged from our hospital and had not had enlargement of the mediastinum or pleural effusion as of November 2000.

In this case we initially failed to demonstrate the thoracic duct with lymphangiography, which is generally performed to visualize lymphatic ducts. One of the possible reasons for this was that the lymph flow from the left foot was diluted by the lymph flow from the small intestine. We subsequently attempted to visualize the thoracic duct with scintigraphy using ${ }^{123} \mathrm{I}$-BMIPP. ${ }^{123} \mathrm{I}$-BMIPP, which is usually used for cardiomyoscintigraphy, is a long-chain fatty acid. When orally administered, it is absorbed by the intestinal lymphatics and then flows and passes through the thoracic duct. Kettner and colleagues ${ }^{5}$ have also reported lymphoscintigraphy with ${ }^{123}$ I-iodophenyl pentadecanoic acid ( ${ }^{123}$ I-IPPA), another type of long-chain fatty acid, to visualize the thoracic duct and to detect sites of lymphatic leakage.

In our hospital ${ }^{123} \mathrm{I}$-IPPA is not used for scintigraphy, whereas ${ }^{132} \mathrm{I}$-BMIPP is commonly used for cardiomyoscintigraphy. We applied ${ }^{123}$ I-BMIPP to visualize the thoracic duct because both materials are similar in structure. 

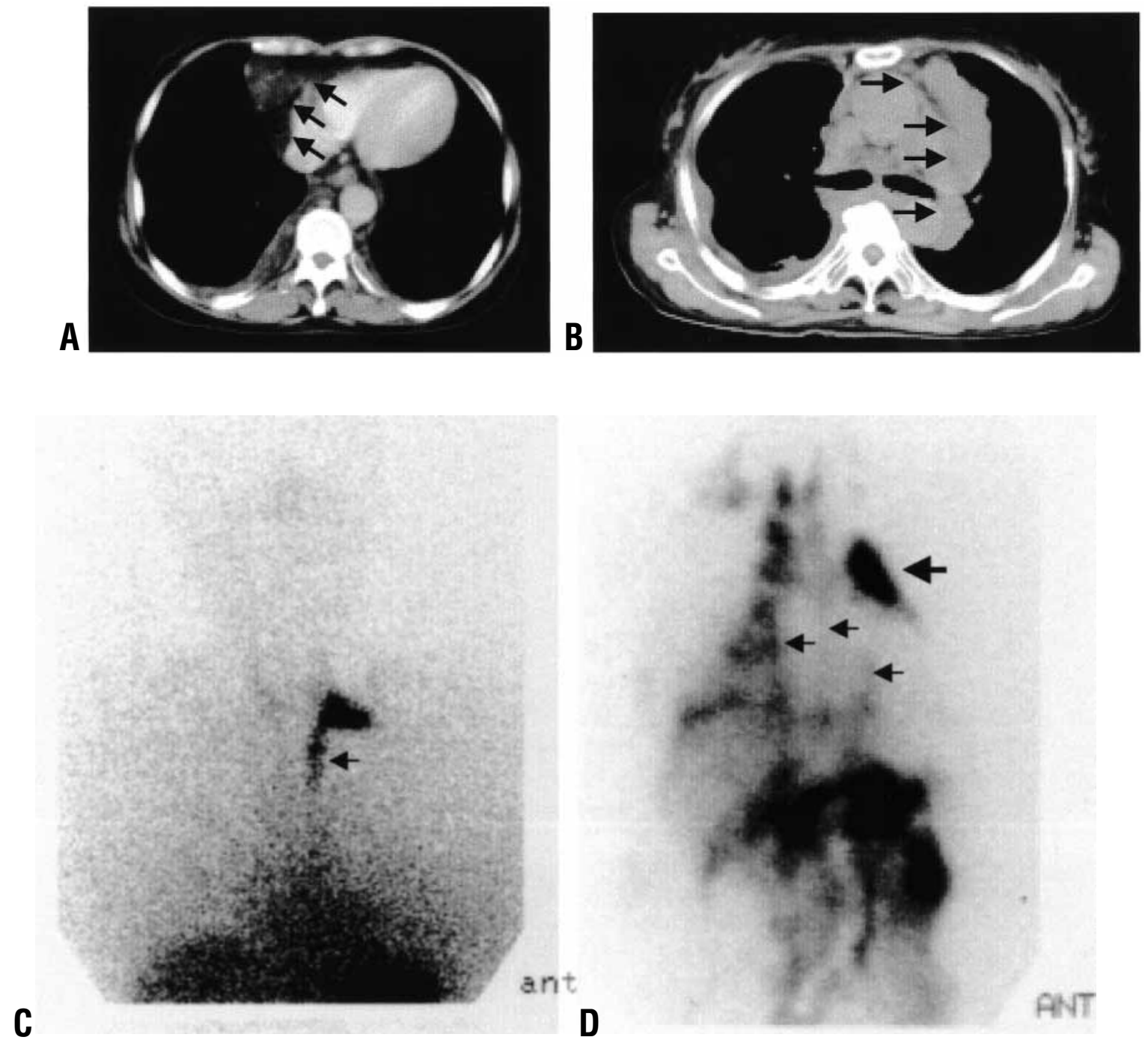

Figure 1. Chest CT and scintiscans after oral administration of ${ }^{123}$ I-BMIPP. A, Chest CT at admission. Arrows indicate a tumor-like mass with fat density. B, Chest CT 13 days after operation. At the left side of the aortic arch, marked accumulation was present. C, Scintiscan of a representative normal volunteer at 100 minutes after oral administration. The small arrow indicates the normal thoracic duct. D, Scintiscan of the patient at 300 minutes after oral administration. There were 3 routes of upward flow (small arrows). In the upper mediastinum 3 transverse communications were also detected. At the left side of the aortic arch, marked pooling of the isotope (large arrow) was also present.

On the basis of our experience, it was easy to visualize the thoracic duct, as well as the collateral circulation, transverse communications, and abnormal accumulation of chyle. In addition, sequential monitoring of plasma ${ }^{123}$ I-BMIPP activities helped us to understand the dynamics of the chyle flow in this patient. We were afraid of complete loss of lymphatic influx into the venous circulation in the present case, but fortunately, this was denied by the results of the examination with ${ }^{123}$ I-BMIPP. Although the pathogenesis of the disease is hardly understood, our experience showed the possibility of understanding of the dynamics of lymph flow in the thoracic duct in diseased individuals. On the basis of the results of scintigraphy, we chose conservative management, resulting in successful control of fluid accumulation in the thorax and mediastinum and eventual discharge of the patient from our hospital.

Our experience showed that lymphoscintigraphy with orally administrated ${ }^{123}$ I-BMIPP and subsequent monitoring of plasma ${ }^{123}$ I-BMIPP activities is useful for understanding diseases of the thoracic duct without any complications or invasiveness. The thoracic duct, collateral flows, leakage site, and abnormal pooling in the mediastinum can be visualized with this method. Combined 


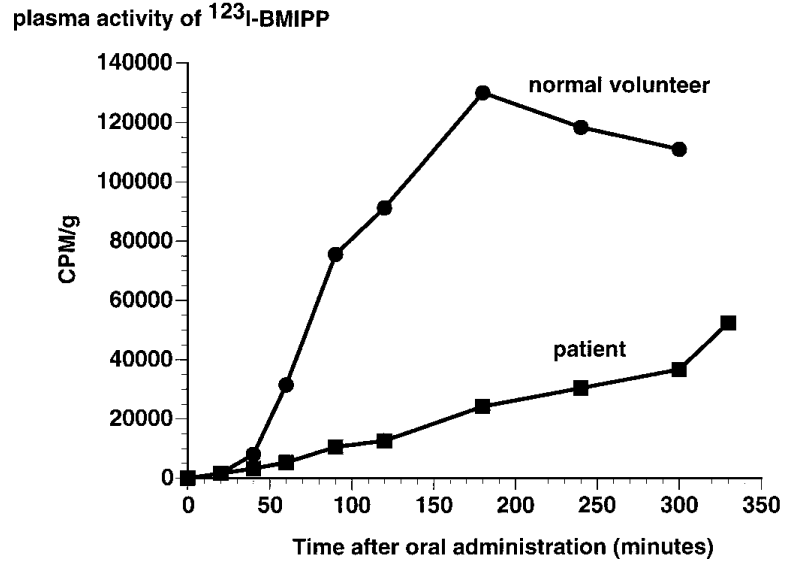

Figure 2. Plasma ${ }^{123}$ I-BMIPP activities after oral administration. with subsequent monitoring of plasma ${ }^{123}$ I-BMIPP activities, the dynamics of thoracic lymph flow can also be elucidated. Thus, these methods may be recommended as safe for patients with diseases of the thoracic duct.

\section{References}

1. Merrigan BA, Winter DC, O'Sullivan GC. Chylothorax. Br J Surg. 1997;84:15-20

2. Browse NL, Allen DR, Wilson NW. Management of chylothorax. Br J Surg. 1997;84:1711-6.

3. Howarth D, Gloviczki P. Lymphocintigraphy and lymphangiography of lymphangiectasia. J Nucl Med. 1998;39:1635-8.

4. Geeter FD, Caveliers V, Pansar I, Bossuyt A, Franken PR. Effect of oral glucose loading on the biodistribution of BMIPP in normal volunteers. J Nucl Med. 1998;39:1850-6.

5. Kettner BI, Aurisch R, Ruckert JC, Sandrock D, Munz DL. Scintigraphic localization of lymphatic leakage site after oral administration of Iodine-123-IPPA. J Nucl Med. 1998;39:2141-4.

\section{Availability of Journal back issues}

As a service to our subscribers, copies of back issues of The Journal of Thoracic and Cardiovascular Surgery for the preceding 5 years are maintained and are available for purchase from Mosby until inventory is depleted. Please write to Mosby, Subscription Customer Service, 6277 Sea Harbor Dr, Orlando, FL 32877, or call 800-654-2452 or 407-345-4000 for information on availability of particular issues and prices. If unavailable from the publisher, photocopies of complete issues may be purchased from Bell \& Howell Information and Learning, $300 \mathrm{~N}$ Zeeb Rd, Ann Arbor, MI 48106-1346; 734-761-4700 or 800-521-0600. 